Fixed Point Theory, 20(2019), No. 2, 581-590

DOI: $10.24193 /$ fpt-ro.2019.2.38

http://www.math.ubbcluj.ro/ nodeacj/sfptcj.html

\title{
GENERALIZED $\Phi$-EPI MAPS AND TOPOLOGICAL COINCIDENCE PRINCIPLES
}

\author{
DONAL O'REGAN \\ School of Mathematics, Statistics and Applied Mathematics \\ National University of Ireland, Galway, Ireland \\ E-mail: donal.oregan@nuigalway.ie
}

\begin{abstract}
In this paper we present the notion of a $\Phi$-epi map for a general class of maps and we present coincidence and homotopy properties for these maps.

Key Words and Phrases: Epi maps, coincidence, homotopy, normalization.

2010 Mathematics Subject Classification: 47H10, 54H25.

\section{INTRODUCTION}

The notion of a 0-epi map was introduced by Furi, Martelli and Vignoli [4] and extended in a variety of settings in the literature by other authors, see for example $[5$, $7,9,11]$. In this paper we present a generalization of $\Phi$-epi maps motivated in part, for example, from continuation theorems of set valued maps which have continuous selections $[1,2]$. In particular we present coincidence, homotopy and normalization properties of these $\Phi$-epi maps.
\end{abstract}

\section{REFERENCES}

[1] R.P. Agarwal, D. O'Regan, Continuation methods for closed, weakly closed, DKT and WDKT maps, Computers Math. with Appl., 38(1999), 81-88.

[2] R.P. Agarwal, D. O'Regan, An essential map theory for $U_{c}^{\kappa}$ and PK maps, Topological Meth. Nonlinear Anal., 21(2003), 375-386.

[3] C.D. Aliprantis, K.C. Border, Infinite Dimensional Analysis, Springer Verlag, Berlin, 1994.

[4] M. Furi, M. Martelli, A. Vignoli, On the solvability of nonlinear operator equations in normed spaces, Ann. Math. Pura Appl., 124(1980), 321-343.

[5] G. Gabor, L. Gorniewicz, M. Slosarski, Generalized topological essentiality and coincidence points of multivalued maps, Set-Valued Anal., 17(2009), 1-19.

[6] L. Gorniewicz, Topological Fixed Point Theory of Multivalued Mappings (second edition), Springer, Dordrecht, 2006.

[7] L. Gorniewicz, M. Slosarski, Topological essentiality and differential inclusions, Bull. Austral. Math. Soc., 45(1992), 177-193.

[8] E. Michael, A selection theorem, Proc. Amer. Math. Soc., 17(1966), 1404-1406.

[9] D. O'Regan, Coincidence methods based on essential and 0-epi maps, Acta Applicandae Math., 54(1998), 319-330. 
[10] D. O'Regan, Fixed point theorems for the $B^{\kappa}$-admissible maps of Park, Applicable Anal., 79(2001), 173-185.

[11] D. O'Regan, Coincidence points for multivalued maps based on $\Phi$-epi and $\Phi$-essential maps, Dynamic Systems and Appl., 24(2015), 143-154.

Received: November 28, 2016; Accepted: Jaunuary 30, $201 \%$. 